\title{
Spectrum of Pathogens Derived from Women Diagnosed with Urinary Tract Infections
}

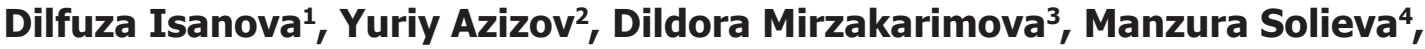 Sherzodjon Abdukodirov5 ${ }^{5}$ Avazbek Kayumov6}

\begin{abstract}
'Ph.D., Docent, Senior Teacher, Department of Phthisiology and Pulmonology, Microbiology, Virology, Immunology, Andijan State Medical Institute, Andijan, Uzbekistan; 'Professor, PhD, Docent, Department of Phthisiology and Pulmonology, Microbiology, Virology, Immunology, Andijan State Medical Institute, Andijan, Uzbekistan, ${ }^{3}$ Ph.D., Docent, Head of Department of Infectious Diseases, Andijan State Medical lnstitute, Andijan, Uzbekistan; 4Ph.D., Docent, Head of Department of General Hygiene, Andijan State Medical Institute, Andijan, Uzbekistan; ${ }^{5}$ Assistant, Department of Infectious Diseases, Andijan State Medical Institute, Andijan, Uzbekistan; ${ }^{6}$ Assistant, Department of Infectious

Diseases, Andijan State Medical Institute, Andijan, Uzbekistan.
\end{abstract}

Factor: $6.1(2018)$ ICV: $90.90(2018)$

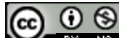

Copyright@IJCRR

\section{ABSTRACT}

Introduction: As a result of large-scale scientific research and fundamental research carried out in the field of medicine in the world, it has been established that one of the most common bacterial infections occurring in humans is infections of the urinary system. These infections are common among populations of all ages. "the incidence of urinary tract infections among newborns is $1.0 \%$, among school-age children $2-3 \%$ (the ratio of boys to girls is $1: 10$ ), in the elderly $20-30 \%$." it is known that there are various microorganisms in the lower part of the urinary tract.

Objective: Several scientific studies are being carried out around the world to achieve high efficiency in improving the diagnosis, treatment, prevention of acute and chronic urinary tract infections.

Methods: In the leading scientific and clinical centres of many countries, research work is being carried out on acute and chronic urinary tract infections, but it remains a priority to determine the degree of variability of taxonomic characteristics of urinary tract infections, the relationship of their virulence with the immunobiological state of the macroorganism, the development of criteria for determining the effectiveness of treatment, mechanisms the formation of a dysbiotic state in various biotopes of women, the creation and implementation of optimal treatment regimens.

Result: In Uzbekistan, along with the accelerated development of the medical sector, which provides high-tech enrichment of modern medical equipment, the correct system of diagnosis and treatment of chronic diseases among women of reproductive age is being introduced.

Conclusion: Fulfilling these tasks for the diagnosis of microbiological characteristics and the peculiarities of the variability of the main taxonomic signs of urinary tract infections in women of reproductive age, raising the level of modern medical care to a new level and further improving the quality of medical services will help reduce the incidence of urinary tract infections among women of reproductive age and improve health.

Key Words: Urinary Tract Infections, Pathogens, Sick women, Purulent-inflammatory processes, Bacteriuria, Pyelonephritis, renal abscess, Carbuncle

\section{INTRODUCTION}

The term "urinary tract infections" refers to the process of purulent-inflammatory processes in the urinary system. At present, there are pathologies of the lower (cystitis, urethritis) and upper parts of the urinary tract (pyelonephritis, renal abscess and carbuncle, apostematous pyelonephritis). ${ }^{1,2}$

The clinical significance of UTI is explained by its prevalence, the complexity of the diagnosis, the negative impact on the health and ability to work of the population, the large investment in the diagnosis and treatment of this pathology. ${ }^{3,4}$ At present, all urinary tract diseases are divided into congenital and lifelong diseases based on the International Classification of Diseases (ICD-10), which was revised 10 times in $2007.2,5,6$

It is known that the human urinary system includes the kidneys (upper urinary tract), urinary organs - urinary tract, bladder (middle urinary tract), urethra (lower urinary tract).

\section{Corresponding Author:}

Dilfuza Isanova, Ph.D., Docent, Senior Teacher, Department of Phthisiology and Pulmonology, Microbiology, Virology, Immunology, Andijan State Medical Institute, Andijan, Uzbekistan; Email: jovohir99@mail.ru

ISSN: 2231-2196 (Print) ISSN: 0975-5241 (Online)

Received: $07.08 .2020 \quad$ Revised: 10.10 .2020

Accepted: 17.11 .2020

Published: 05.01 .2021 
The tissues and cells of these organs perform the functions of separating urine from the blood, expelling it from the body, and expelling it. ${ }^{7}$

The literature suggests that the urinary tract of healthy women is normally sterile, free of various microorganisms, while in men, some urinary tract genital system biotope-specific normative microflora are present, albeit in small amounts. , $^{2,4}$

It has been shown that urination is a complex reflex process that occurs when at least 250-300 $\mathrm{ml}$ of urine accumulates in the bladder in normally healthy people. Normally, urination occurs 4-6 times a day, and in all healthy people, urine is normally sterile. ${ }^{3,9}$ There is no difference between men and women in this pathophysiological process.

Uroepithelial cells in the urinary tract produce a mucopolysaccharide substance that forms a protective layer that is a covering and antiadhesive factor and separates it on the surface of the urinary tract mucosa. The formation of this mucopolysaccharide layer is a hormone-dependent process produced in the body. While estrogens affect its synthesis, progesterone affects its release from epithelial cells. ${ }^{7}$ Normally, a low value of urinary $\mathrm{pH}$ has a bacteriostatic effect, characterized by high concentration and osmolarity of urea. ${ }^{5,9}$

The occurrence of bacteria of different generations and types, specific and non-specific inhibitors, A, G, secretory immunoglobulins A (IgA, IgG, sIgA) are observed in human urine. $^{6}$

\section{MATERIALS AND METHODS}

To complete this dissertation, a total of 1026 women of childbearing age (18-49 years) with UTI (Main group) and healthy (control group) were involved in the article. Their urine samples were bacteriologically examined. Clinical material was obtained from sick leaves and outpatient cards.

The examined women of childbearing age (Main group, $\mathrm{n}=$ 986) were divided into age groups as follows:

- 18-35 years - mature reproductive age $(\mathrm{n}=578,58.6 \pm$ $1.6 \%)$;

- 36-49 years - late reproductive age $(n=408,41.4 \pm 1.6 \%)$.

Healthy women of childbearing age $(n=40)$ included in the control group formed for comparison were also distributed by the following age groups:

- 18-35 years - mature reproductive age $(n=25,62.5 \pm$ $7.6 \%)$;

- 36-49 years - late reproductive age $(n=15.37 .5 \pm 7.6 \%)$.

The group of women with UTI did not include women with occupational diseases that adversely affect the condition of the urinary tract, women with urinary tract infections caused by specific pathogens (tuberculosis, gonorrhoea, trauma, etc.), urinary tract tumours, chronic nephrological diseases.

The group of healthy women included women who did not have UTI, who did not have symptoms typical of such diseases in the last 2 years, whose age, lifestyle, living conditions were representative with the group of sick women.

The other control group consisted of healthy males of the same age $(18-49$ years $)(n=30)$. Their urine samples were also bacteriologically examined, as were those of women.

Andijan (sick women - $\mathrm{n}=628,63.7 \pm 1.5 \%$; healthy women $-\mathrm{n}=23,57.5 \pm 7$ ) in order to compare the results of microbiological studies to determine whether there are regional differences between UTI pathogens in relation to the location of patients , 8\%) and Khorezm regions (sick women - $\mathrm{n}$ $=358,36.3 \pm 1.5 \%$; healthy women $-\mathrm{n}=17,42.5 \pm 7.8 \%$ ).

Of all the women of childbearing age (18-49 years) involved in microbiological studies, 194 patients $(\mathrm{n}=986)$ were diagnosed with acute UTI, 84 with chronic UTI (total $n=278$ ) using clinical, laboratory-instrumental methods, bacteriological confirmed using methods.

\section{RESULTS}

To compare the results obtained during the study, we gave the level of detection of uroinfectious pathogens by gender. Clinically significant bacteriuria $\left(10^{5} \mathrm{CFU} / \mathrm{ml}\right.$ and more $)$ were considered urinary tract infectious pathogens isolated from the largest dilution of urine.

Clinically significant bacteriuria in 278 samples $(28.2$ $\pm 1.4 \%$ ), non-clinically significant bacteriuria (less than $\left.10^{5} \mathrm{CFU} / \mathrm{ml}\right)$ in 528 samples $(53.5 \pm 1.6 \%)$, sterile urine samples in 180 cases ( $18.2 \pm 1.2 \%$ ) were detected (Figure 3.1). Advanced microbiological studies in the next phase involved sick women $(n=278)$ with clinically significant bacteriuria and isolated pathogens (Figure 1).

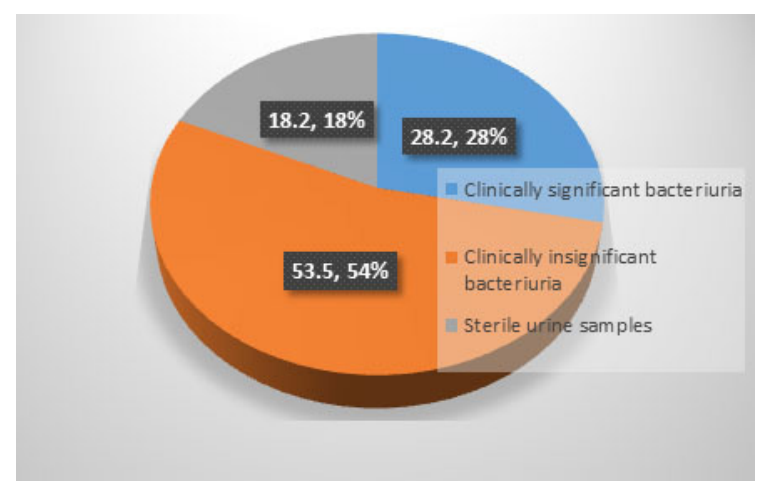

Figure 1: The occurrence of urinary tract infectious pathogens depending on clinical significance (more or less than $10^{5} \mathrm{CFU} /$ $\mathrm{ml}, \%)$. 
The results showed that the etiological role of gram-negative bacteria was close to each other in women of childbearing age and men of the same age (Table 1). Escherichia coli accounted for the majority $(59.4 \pm 2.9 \%, \mathrm{n}=165)$ of the 278 strains isolated from women of childbearing age UTI observed. A similar situation was observed in male patients. Other representatives of Enterobacteriaceae were characterized by the fact that Klebsiella pneumonia, Proteus Vulgaris, Enterobacterales and Citrobacter freundii were significantly less isolated than Escherichia coli $(\mathrm{P}<0.001)$. The high percentage of occurrence of P.aeruginosa among uropathogenic microorganisms $(4.0 \pm 1.2 \%, \mathrm{n}=11)$ was also interpreted as a noteworthy condition.

It was found that the high incidence of hemolytic Escherichia coli $(6.8 \pm 1.5 \%, \mathrm{n}=19)$ is one of the signs that the pathological process is becoming chronic, as these strains have formed a pathogenic feature along with long persistence in this biotope.

Table 1: Picture of pathogens isolated from urine samples of women with urinary tract infections of childbearing age

\begin{tabular}{|c|c|c|c|c|}
\hline \multirow[t]{2}{*}{ Pathogen } & \multicolumn{2}{|c|}{$\begin{array}{l}\text { Sick women of } \\
\text { childbearing age, } \\
n=278\end{array}$} & \multicolumn{2}{|c|}{$\begin{array}{l}\text { Sick men of the } \\
\text { same age, } \\
\quad n=25\end{array}$} \\
\hline & Absolute & $\%$ & Absolute & $\%$ \\
\hline S.epidermidis & 17 & $6.1 \pm 1.4$ & 2 & $8.0 \pm 5,4$ \\
\hline S.aureus & 6 & $2.2 \pm 0.9$ & 2 & $8.0 \pm 5,4$ \\
\hline S.haemolyticus & 5 & $1.8 \pm 0.8$ & 2 & $8.0 \pm 5.4$ \\
\hline S.saprophyticus & 5 & $1.8 \pm 0.8$ & - & - \\
\hline S.viridans & 3 & $1.1 \pm 0.6$ & - & - \\
\hline E.faecalis & 11 & $4.0 \pm 1.2$ & 1 & $4.0 \pm 3.9$ \\
\hline $\begin{array}{l}\text { Gram-negative } \\
\text { flora (total) }\end{array}$ & 47 & $16.9 \pm 2.2$ & 7 & $28.0 \pm 9.0$ \\
\hline E.coli & 165 & $59.4 \pm 2.9$ & 14 & $56.0 \pm 9.9$ \\
\hline Hemolytic E.coli & 19 & $6.8 \pm 1.5$ & 1 & $4.0 \pm 3.9$ \\
\hline $\begin{array}{l}\text { Enterobacter } \\
\text { spp. }\end{array}$ & 5 & $1.8 \pm 0.8$ & - & - \\
\hline Citrobacter spp. & 2 & $0.7 \pm 0.5$ & - & - \\
\hline Proteus spp. & 6 & $2.2 \pm 0.9$ & 1 & $4.0 \pm 3.9$ \\
\hline
\end{tabular}

\begin{tabular}{lcccc} 
Klebsiella spp. & 12 & $4.3 \pm 1.2$ & 1 & $4.0 \pm 3.9$ \\
P.aeruginosa & 11 & $4.0 \pm 1.2$ & 1 & $4.0 \pm 3.9$ \\
$\begin{array}{l}\text { Gram-negative } \\
\text { flora (total) }\end{array}$ & 220 & $79.1 \pm 2.4$ & 18 & $72.0 \pm 9.0$ \\
Candidaspp. & 8 & $2.9 \pm 1.0$ & - & - \\
Bacteroidesspp & 3 & $1.1 \pm 0.6$ & - & - \\
\hline
\end{tabular}

The predominance of Gram-positive cocci in S. Epidermidis $(6.1 \pm 1.4 \%, \mathrm{n}=17)$ in $\mathrm{S}$. aureus $(2.2 \pm 0.9 \%, \mathrm{n}=6)$ did not differ significantly from the results of other researchers' Scientific sources [5]. Significantly more identification of gram-negative bacteria than gram-positive cocci in both sexes studied (4.7 times in women, 2.6 times in men - $\mathrm{R}<0.001$ ) was interpreted and evaluated only as a specific case of these infections.

Looking at the gender differences, no convincing difference was observed in the incidence rate of the pathogens. Unlike women, hemolytic strains of E.coli, as well as anaerobes (Bacteroides spp) and microscopic fungi (Candida spp), were not identified in sick men. In the next phase of our research, we studied and evaluated the distribution of pathogens grown from urine samples of women of childbearing age diagnosed with UTI according to the manifestations of the disease (acute and chronic) (Table 2).

The results showed that we did not observe practically different characteristics in terms of the occurrence rate of gram-negative cocci. Acute and chronic UTIStimuli showed similar results in terms of meeting percentages. Since the results obtained did not differ significantly from each other $(\mathrm{R}>0.05)$, we did not find it necessary to analyze these figures and focus on them separately. However, we have witnessed a different picture of gram-negative bacteria, especially members of the Enterobacteriaceae family. Although Escherichia coli was more common in acute UTI than in chronic (R0.05) $(62.9 \pm 3.5 \%, \mathrm{n}=122$, and $51.1 \pm 5.5 \%$, respectively, $\mathrm{n}=$ 43) we observed the opposite of hemolytic Escherichia coli.

Although strains of these pathogens are not convincing, they are more common in chronic UTI. One of the main reasons for this was considered to be the appearance of hemolytic Escherichia coli as a result of the long persistence of the pathogen in the body.

Table 2: Distribution of pathogens grown in the urine of women with urinary tract infections depending on the appearance of the disease

\begin{tabular}{lcccccc} 
Pathogen & \multicolumn{2}{c}{ Acute UTI, $\mathbf{n}=\mathbf{1 9 4}$} & \multicolumn{2}{c}{ Chronic UTI, $\mathbf{n = 8 4}$} & \multicolumn{2}{c}{ Total, $\mathbf{n = 2 7 8}$} \\
& Absolute & $\%$ & Absolute & $\%$ & Absolute & $\%$ \\
S. epidermidis & 12 & $6.2 \pm 1.7$ & 5 & $5.9 \pm 2.6$ & 17 & $6.1 \pm 1.4$ \\
S.aureus & 4 & $2.1 \pm 1.0$ & 2 & $2.4 \pm 1.7$ & 6 & $2.2 \pm 0.9$ \\
S.haemolyticus & 4 & $2.1 \pm 1.0$ & 1 & $1.2 \pm 1.1$ & 5 & $1.8 \pm 0.8$ \\
S.saprophyticus & 3 & $1.5 \pm 0.9$ & 2 & $2.4 \pm 1.7$ & 5 & $1.8 \pm 0.8$
\end{tabular}


Table 2: (Continued)

\begin{tabular}{|c|c|c|c|c|c|c|}
\hline \multirow[t]{2}{*}{ Pathogen } & \multicolumn{2}{|c|}{ Acute UTI, n=194 } & \multicolumn{2}{|c|}{ Chronic UTI, n=84 } & \multicolumn{2}{|c|}{ Total, $\mathrm{n}=278$} \\
\hline & Absolute & $\%$ & Absolute & $\%$ & Absolute & $\%$ \\
\hline S.viridans & 2 & $1.0 \pm 0.7$ & 1 & $1.2 \pm 1.1$ & 3 & $1.1 \pm 0.6$ \\
\hline E.faecalis & 8 & $4.1 \pm 1.4$ & 3 & $3.6 \pm 2.0$ & 11 & $4.0 \pm 1.2$ \\
\hline Gram-negative flora (total) & 33 & $17.0 \pm 2.7$ & 14 & $16.7 \pm 4.1$ & 47 & $16.9 \pm 2.2$ \\
\hline E.coli & 122 & $62.9 \pm 3.5$ & 43 & $51.1 \pm 5 \cdot 5$ & 165 & $59.4 \pm 2.9$ \\
\hline Hemolytic E.coli & 13 & $6.7 \pm 1.8$ & 6 & $7.1 \pm 2.8$ & 19 & $6.8 \pm 1.5$ \\
\hline Enterobacter spp. & 2 & $1.0 \pm 0.7$ & 3 & $3.6 \pm 2.0$ & 5 & $1.8 \pm 0.8$ \\
\hline Citrobacter spp. & o & - & 2 & $2,4 \pm 1,7$ & 2 & $0,7 \pm 0,5$ \\
\hline Proteus spp. & 2 & $1.0 \pm 0.7$ & 4 & $4 \cdot 7 \pm 2 \cdot 3$ & 6 & $2.2 \pm 0.9$ \\
\hline Klebsiella spp. & 9 & $4.6 \pm 1.5$ & 3 & $3.6 \pm 2.0$ & 12 & $4 \cdot 3 \pm 1.2$ \\
\hline P.aeruginosa & 9 & $4.6 \pm 1.5$ & 2 & $2.4 \pm 1.7$ & 11 & $4.0 \pm 1.2$ \\
\hline Gram-negative flora (total) & 157 & $80.9 \pm 2.8$ & 63 & $75 \cdot 0 \pm 4 \cdot 7$ & 220 & $79.1 \pm 2.4$ \\
\hline Candidaspp. & 3 & $1.5 \pm 0.9$ & 5 & $5 \cdot 9 \pm 2.6$ & 8 & $2.9 \pm 1.0$ \\
\hline Bacteroidesspp & 1 & $0.5 \pm 0.4$ & 2 & $2.4 \pm 1.7$ & 3 & $1.1 \pm 0.6$ \\
\hline
\end{tabular}

Enterobacterales $1.0 \pm 0.7 \%, \mathrm{n}=2$ versus $3.6 \pm 2.0 \%, \mathrm{n}=$ 3 , respectively, when enterobacteria were chronically more common than acute $(\mathrm{R}<0.05) ; 2.4 \pm 1.7 \%$ against Citrobacter spp 0; Proteus Vulgaris $1.0 \pm 0.7 \%, \mathrm{n}=2$ versus $4.7 \pm$ $2.3 \%, \mathrm{n}=4$. However, due to the small number of figures obtained, it was not possible to draw certain laws based on them. Similar results were observed for other isolated pathogens.

It should be noted that in both cases, the incidence of gramnegative bacteria was significantly higher than the incidence of gram-positive cocci $-17.0 \pm 2.7 \%$, respectively, in acute UTI, $80.9 \pm 2.8 \%$ against $\mathrm{n}=33, \mathrm{n}=157(\mathrm{R}<0.001) ; 16.7$ $\pm 4.1 \%$ in chronic UTI, $75.0 \pm 4.7 \%$ against $n=14, n=63$ $(\mathrm{R}<0.001)$. However, in both forms of the disease, it should be borne in mind that this is mainly due to the uropathogenic Escherichia coli and its hemolytic strains. The results of the analysis showed that in clinically significant bacteriuria (n $=278$ ) monocultures of pathogens were isolated, no associations of microorganisms were observed. Significantly, this condition manifested uniformly in the acute and chronic manifestations of these infections and differed significantly from other studied purulent-inflammatory diseases.

\section{DISCUSSION}

It is noteworthy that the results obtained differed significantly from the purulent-inflammatory diseases cited as the results of the work of other researchers. ${ }^{9,10,13}$ in other words, associations of microorganisms were observed in them in all cases. In our opinion, this situation is explained Mainly by the fact that the disease is treated mainly in an outpatient setting, there is a lack of hospitalization in hospitals and a significant decrease in the proportion of antibiotic-resistant strains. ${ }^{6}$

It is known that in the dynamics of various purulent-inflammatory diseases, including acute and chronic UTI, the exchange of pathogens is of great importance for the tactics of treatment and the prospects of its outcome. ${ }^{9}$

Given that the transfer of one pathogen to another in the dynamics of disease transmission plays an important role in determining the outcome of the disease, we have studied and evaluated this indicator comparatively with the manifestations of the disease. It was found that in acute UTI $(n=194)$ the exchange of pathogens was low - only in 3 cases (1.5 \pm $0.9 \%$ ), in which case in 2 cases Enterobacter spp., In 1 case Proteus spp was exchanged with Escherichia coli.

Even in the chronic form of the infection, no significant difference was found in the acute. The difference is the relatively large number of exchanges and the exchange of grampositive cocci for gram-negative bacteria. ${ }^{10-12}$ The exchange of non-pathogenic microorganisms with pathogenic and conditionally-pathogenic strains, as well as with bacteria belonging to the strains of nosocomial infections (nosocomial infections) showed that the chronic process in the patient develops slowly and the prognosis of this disease is unfavourable.

\section{CONCLUSIONS}

The bacteriological diagnostic value of the microbiological characteristics, properties of the variability of pathogens sown from urine samples of women of reproductive age with urinary tract infections were evaluated. The system for assessing the 
detection of the "rainbow corolla" phenomenon was substantiated as an additional test for identifying the pathogen Pseudomonas aeruginosa in bacteriological laboratories for urinary tract infections in women. Substantiated the use of urine antiadhesive properties in the differential diagnosis of acute and chronic urinary tract infections in women of reproductive age. It is recommended in public health practice to determine the skin auto-microflora as an additional criterion to determine the effectiveness of treatment, to predict the outcome of urinary tract infection. The reliability of the research results is substantiated using theoretical approaches and methods, methodically correctly performed microbiological studies, the sufficiency of the number of urine samples taken, the processing of the material by statistical research methods, confirmation of the results and conclusions. The scientific significance of the research results lies in the fact that the diagnostic value of the variability of the taxonomic signs of urinary tract pathogens in women of reproductive age is determined, a method for determining the degree of adhesiveness of uropathogenic strains is recommended, the need to use the antiadhesive activity of urine of women for differential diagnosis of acute and chronic urinary tract infections, microbiocenosis is determined skin to assess the degree of dysbiosis of biotopes of the body, the recommendation of this method as a criterion for predicting the outcome of the chronic form of the disease.

\section{ACKNOWLEDGMENT}

Authors acknowledge the immense help received from the scholars whose articles are cited and included in references to this manuscript. The authors are also grateful to authors / editors / publishers of all those articles, journals, and books from which the literature for this article has been reviewed and discussed.

\section{Conflict of Interest: None}

Financial Support: None

\section{REFERENCES}

1. Abdullaev RK, Tojieva ZB. Diagnostic value of bacteriological examinations in urinary tract infections. J Theo Clin Med 2014;2:31-33.

2. Apolikhina IA, Glybochko PV, Teterina TA. Genetic predisposition to the development of uncomplicated urinary tract infections and refractory overactive bladder in women. Expt Clin Urol 2012;4:14-19.

3. Alekseenko IV, Ivanova LA. The modern view of the problem of urinary tract infections in pregnant women with type 1 diabetes. Int J App Fund Res 2016; 12:1174-1179.

4. Alekseenko IV, Ivanova LA, Arkhipov EV, Sigitova ON. Urinary tract infections in pregnant women: modern recommendations for diagnosis and treatment. Bull Mod Clin Med 2016;9(6):109-114.

5. Beloglazova IP, Troshina AA, Poteshkina NG. Urinary tract infections: part I. Gen Med 2018;1:18-24.

6. Voshchula VI, Vilyukha AI. Uncomplicated lower urinary tract infection in women and its prevention. Arsmedica 2012; 5:98104.

7. Valyshev AV, Elagin NN, Bukharin OV. Anaerobic microflora of the female reproductive tract. Gen Med 2001;4:78-84.

8. Barkanova ON, Modern views on antibiotic therapy of uncomplicated urinary tract infections. Bull. Mod. Clin. Med .2012;4:108-113.

9. Bereznyakov IG. Features of diagnosis and treatment of lower urinary tract infections in women. Med Asp Wom Health 2006; 1: 38-43.

10. Hajiyeva ZK. Features of the approach to the diagnosis and treatment of recurrent infections of the lower urinary tract. Urology 2013;3:84-90.

11. Gadzhieva ZK, Kazilov YB. Features of the approach to the prevention of recurrent lower urinary tract infections. Urology 2016;3: 65-76.

12. Venkata NM, Debnath BD. Identification of Parasite Presence on Thin Blood Splotch Images. Int J Curr Res Rev 2020;12(19):408 . 